\title{
Uma perspectiva da palhaçaria contextualizada ao hospital: entrevista com Ésio Magalhães
}

\section{A perspective of hospital clowning: interview with Esio Magalhães}

Daiani Cezimbra Severo Rossini Brum ${ }^{1}$ Karenine de Oliveira Porpino ${ }^{2}$ 


\section{Resumo}

Este trabalho trata-se de uma apresentação do artista cênico Ésio Magalhães, do grupo Barracão Teatro de Campinas (SP), bem como do compartiIhamento na íntegra da entrevista cedida por ele para nossa pesquisa de Mestrado na área de Artes Cênicas, que se encontra em andamento. Ésio atualmente é tido enquanto referência no que tange a palhaçaria brasileira, e aqui gentilmente tece considerações sobre sua perspectiva em relação à atuação palhacesca hospitalar, assim como sobre a composição de seu oficio: palhaço.

Palavras-chave: Artes Cênicas; paIhaçaria hospitalar; Ésio Magalhães

\section{Abstract}

This work it is a presentation of the scenic artist Ésio Magalhães, of the Barracão Theater group (Campinas, SP), as well as sharing in full the interview given by him to our Performing Arts Master's research in progress. Ésio is currently taken as a reference regarding the Brazilian clowning, and here gently reflects on his perspective on hospital clown performance, as well as on the composition of his office: clown.

Keywords: Performing Arts; hospital clowning; Ésio Magalhães

ISSN: 1414.5731

E-ISSN: 2358.6958

\footnotetext{
Mestranda em Artes Cênicas, Universidade Federal do Rio Grande do Norte (UFRN). daianisevero@gmail.com

2 Profa. Dra. associada da Universidade Federal do Rio Grande do Norte (UFRN), atua no Curso de Licenciatura em Dança e nos Programas de Pós-graduação em Educação e Artes Cênicas. kporpino@gmail.com
} 
O presente trabalho trata da apresentação do artista brasileiro Ésio Magalhães e de posterior compartilhamento de uma entrevista cedida por ele para nossa pesquisa de Mestrado em Artes Cênicas que se encontra em andamento. A entrevista foi realizada em julho de 2016, e conta com dez questões que têm como mote central a investigação sobre a atuação palhacesca hospitalar na percepção do entrevistado. Ésio atuou como palhaço na Organização Não Governamental (ONG) Doutores da Alegria $^{3}$ sendo que se destacam suas contribuições na arte da palhaçaria brasileira também em outros âmbitos sociais, tais como o teatro, o circo e a rua.

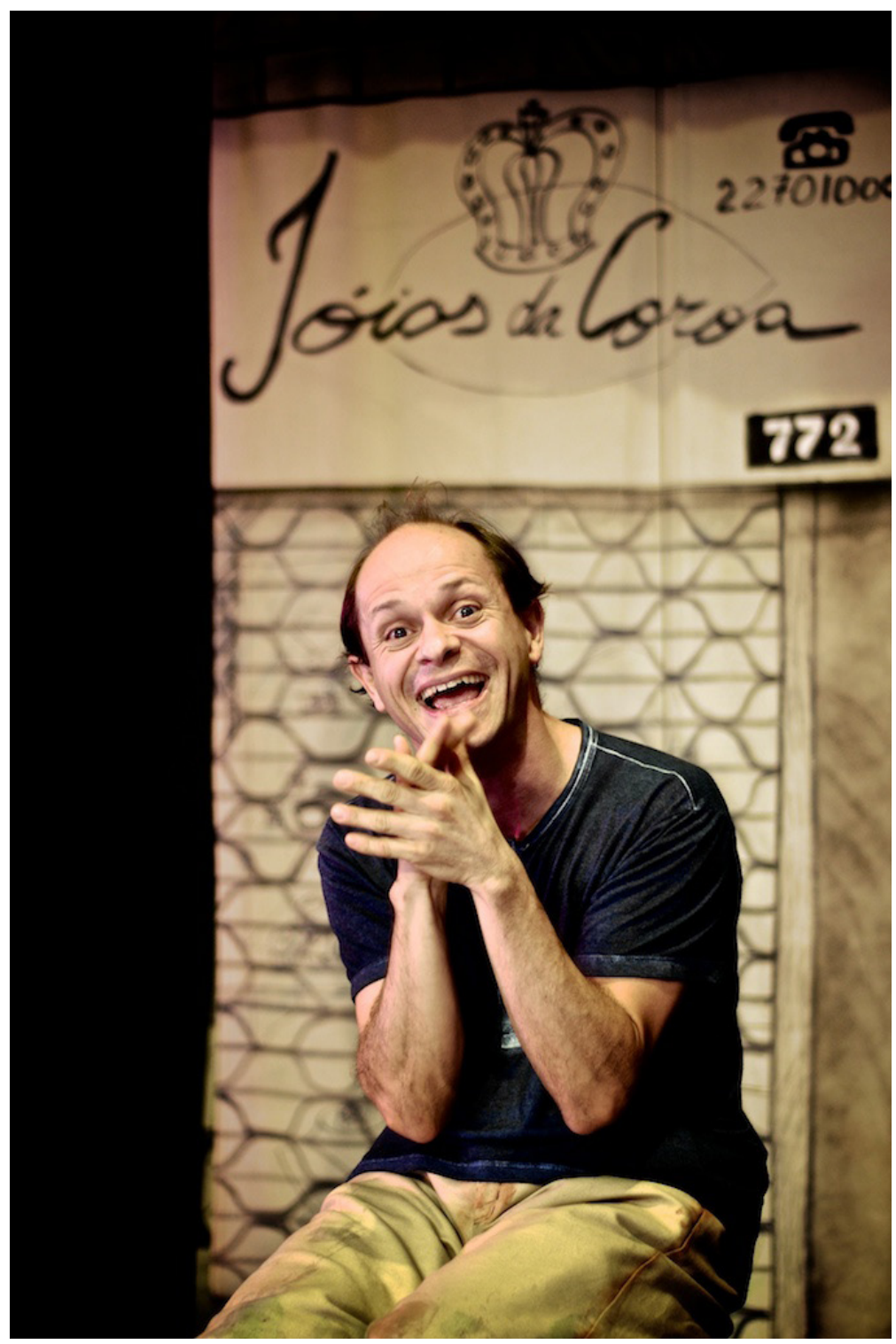

Ésio Magalhães. Foto: Bob Sousa.

${ }^{3}$ A ONG Doutores da Alegria atua desde 1991 a partir da inserção palhaças e palhaços profissionais em palcos hospitalares. Nesses vinte e quatro anos de trabalho ininterrupto, a ONG tornou-se uma importante instituição, sendo referencia no Brasil e no mundo. Os Doutores da Alegria constituem-se enquanto "[...] a única organização no mundo que evoluiu do trabalho no hospital para atividades que também priorizam a formação, a pesquisa e a geração de conteúdo para a sociedade." (Doutores da Alegria, 2014, p.1). 
Nascido em Minas Gerais, Ésio Magalhães fundou em 1998, juntamente com Tiche Viana, o grupo Barracão Teatro. Nestes anos de existência as principais características dos trabalhos do grupo são a pesquisa sobre "[...] o teatro popular com base na máscara teatral, no palhaço, na commedia dell'arte, na improvisação e no aprofundamento da atuação como veículo de expressão cênica." (Barracão Teatro, 2016).

Atualmente o Barracão Teatro conta com diversos espetáculos em seu repertório, com os quais realiza circulações pelo Brasil e no exterior. Além destas ações artísticas, o Barracão Teatro frequentemente realiza oficinas, cursos intensivos e workshops, figurando enquanto importante referência para grupos, artistas e organizações brasileiras que pesquisam a atuação artística no campo da comicidade e das máscaras.

Ésio Magalhães, o palhaço Zabobrim Macambira Birabora Borge Júnior de Alencar (Kásper, 2004) destaca-se pela originalidade e mescla de características teatrais, circenses e de suas práticas hospitalares, repletas de intensas relações com o público em momentos de atuação.

O artista possui vasta formação na área da palhaçaria, tendo estudado com mestres como a canadense Sue Morison, o argentino Fernando Chacovachi, entre outros. Atuou com o palhaço italiano Lerris Colombaioni, nos espetáculos Un Giro Nel Cielo e Circo Ercolino; participou da XII Sessão da Universidade do Teatro Eurasiano - encontro de pesquisadores de teatro de diversos países, sob coordenação de Eugenio Barba, na Itália; em parceria com Tiche Vianna foi responsável pela preparação corporal dos atores na primeira jornada da micro série exibida pela Rede Globo de Televisão Hoje É Dia de Maria, exibida no ano ano de 2005.

Ésio recebeu ainda diversos reconhecimentos, indicações e prêmios em sua área de atuação artística ${ }^{4}$. Recentemente, no ano de 2014, o artista foi convidado pela Companhia de Palhaços Cromossomos para exercer a função de diretor artístico de uma circulação humanitária internacional de palhaços. A expedição se deu através da organização mundial Palhaços sem Fronteiras, que criada em 1993 proporciona expedições em áreas de risco mundiais, tais como campos de refugiados, zonas de conflito, exclusão social.

A partir destas e outras experiências, Ésio constituiu-se no artista e ser humano cuja perspectiva se nos apresenta nas linhas que se seguem. Por ele gentilmente compartilhadas, estas linhas dizem respeito às percepções do artista enquanto palhaço que atuou em diversos espaços da sociedade, e que aqui enfatiza suas vivências artísticas no contexto hospitalar.

\footnotetext{
${ }^{4}$ Tais como o de melhor ator no segundo Festival de Guarulhos (SP) pelo espetáculo de máscara: "Ninguém", direção Tiche Vianna, em 1999; melhor palhaço do ano no Sarau dos Charles em São Paulo em 2002; melhor espetáculo de rua do Júri Oficial e melhor espetáculo do Júri Popular no sétimo Festival de Teatro de Americana com o espetáculo "O Pintor" em 2003; melhor ator, melhor espetáculo do Júri Oficial e melhor espetáculo do Júri Popular no sétimo Festival de Monólogos de Vitória (ES) com o espetáculo "WWW para Freedom" em 2004; melhor espetáculo do Júri Popular, no XIII Concurso de Monólogos Ana Maria Rego I Teresina (PI) com o espetáculo "WWW para Freedom" em 2005; foi indicado como melhor ator no $1^{\circ}$ Prêmio Quem, da revista Quem, pelo espetáculo "A Julieta e o Romeu" em 2007; foi indicado ao Prêmio Shell pelo espetáculo "A Julieta e o Romeu" como melhor ator em 2007; em 2008 foi Indicado ao Prêmio Shell como melhor ator pelo espetáculo "Encruzilhadas entre a Barbárie e o Sonho".
} 


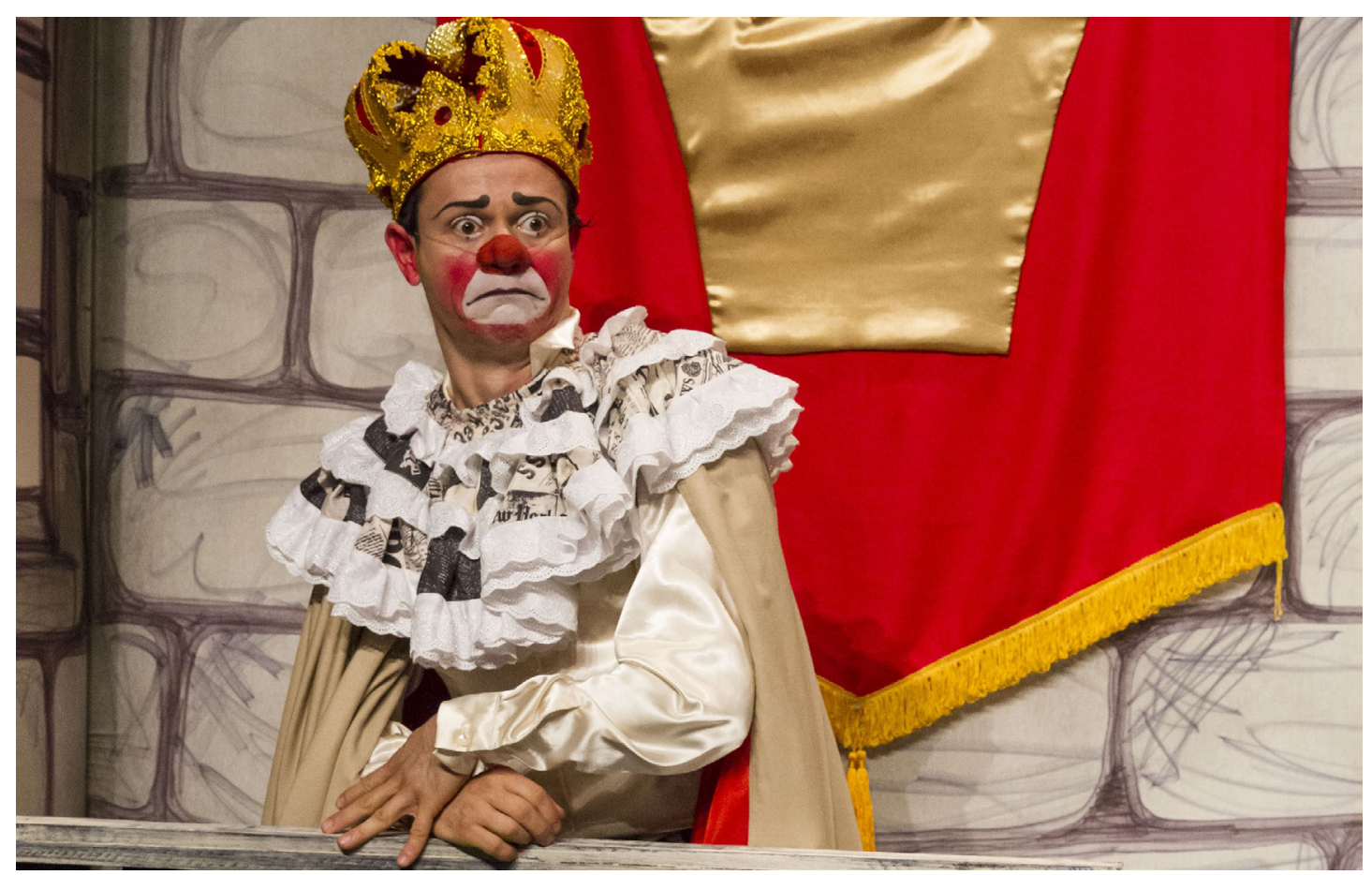

Ésio Magalhães. Foto: Paula Poltronix.

Ésio, eu gostaria de pedir que você contasse um pouco das experiências que te levaram até a atuação no contexto hospitalar. $O$ que te fez buscar esta vivência?

O que me fez procurar os Doutores da Alegria foi à vontade de continuar e intensificar o trabalho com o palhaço que já tinha se iniciado antes, em 1992. Em 1995, fiz o meu primeiro trabalho como palhaço em escolas de Diadema e fiquei trabalhando neste contexto escolar de ensino médio até 1997. Para mim, o contato com o público é importante para o exercício do palhaço, que em seu estado extra cotidiano deve reagir aos inúmeros estímulos externos, vindo do público, do espaço ou do ambiente onde se encontra. Claro que também tem a questão profissional, que efetiva o fazer e a possibilidade de se manter a partir do seu próprio trabalho. Reafirmando a ideia do exercício, creio que o profissional se define não pela sua formação somente, mas muito mais pelas experiências que tem à medida que exerce seu trabalho em contato com o público para o qual ele se destina.

\section{Qual foi seu período de atuação no elenco dos Doutores da Ale- gria?}

Entre 1998 e 2003

Ao adentrar como palhaço no contexto hospitalar, você percebeu diferenças e semelhanças em relação a outros espaços de atuação? Se sim, poderia citar algumas que te marcaram?

Sim, percebi algumas diferenças logo que entrei no hospital. Para mim, as prin- 
cipais diferenças de atuação entre apresentar um espetáculo para um público que te espera e interagir num contexto hospitalar, têm duas naturezas: a espacial e a artística. Dentro da natureza espacial, vejo a questão da dimensão da atuação como uma diferença, pois num espetáculo a adequação espacial se dá antes que o público chegue, ou seja, o artista prepara os locais de atuação, percebe onde estará o público e faz previamente a adaptação do seu material ao espaço possível. Já no hospital, por mais que se conheça o espaço, o artista deve o tempo todo estar atento às modificações deste, pois é um espaço móvel, de passagem, por conseguinte, transitório. $O$ público também se desloca e se move no espaço, então o artista deve ajustar o seu repertório ao mesmo tempo em que se apresenta. Desta forma, o palhaço no hospital deve redimensionar todo o tempo as suas possibilidades de interação para preservar o campo de atuação possível e seguro. Outra diferença de natureza espacial, para mim, é o contexto hostil à apresentação artística, pois a finalidade do hospital não é propiciar uma experiência com as artes para seu público, mas buscar a cura para quem dela necessita. Existe algo muito mais importante que pode levar a atenção deste público para longe: os cuidados com a saúde de quem está ali. Esta diferença espacial se reflete em outra diferença de atuação, mas de natureza artística. $\mathrm{O}$ artista dentro do hospital está à serviço da disponibilidade e possibilidade do público. Não é o público que deve se adequar ao contexto do espetáculo, mas o artista que deve estar atento ao ambiente em que adentra para saber desde o que vai propor até o tempo de duração de seu trabalho que pode ser até interrompido por qualquer questão mais urgente. Neste sentido, o artista deve, se colocando a serviço, ter um permanente desapego ao que veio fazer para poder criar o melhor caminho para a interação. O público no hospital não está, a princípio, disponível ou interessado na interação e o palhaço deve conquistar a atenção da plateia antes de começar sua atuação. Paradoxalmente, há uma leve semelhança com a atuação espontânea do artista na rua, que também deve chamar a atenção do público antes de começar a atuar e deve manter a atenção do público até o final de sua atuação.

\section{Para você, a abertura para o outro (parceiro de cena, crianças e demais pessoas presentes no hospital) é fator fundamental na atua- ção do palhaço neste contexto? Por quê?}

Sim. Creio que a abertura para o outro é fator fundamental para o trabalho do palhaço. Não só no hospital, mas onde quer que ele interaja. O palhaço conquista a cumplicidade com o público pelo riso e para isso precisa abrir o seu trabalho, compartilhar com o outro. Como a improvisação está muito presente no contexto hospitalar, o palhaço precisa estar muito atento a todas as possibilidades para sua atuação. Um bom palhaço de hospital percebe o que o cerca e não perde as possibilidades de jogo. E jogar é estar aberto a todas as jogadas, sejam elas favoráveis ou não.

\section{Você acredita que as palhaças e os palhaços podem impactar ou modificar o cotidiano hospitalar? Se sim, a partir de que elementos?}

Sim! Eu tenho absoluta certeza que a presença do palhaço modifica o cotidiano 
hospitalar. Primeiramente pela questão visual. Ao entrarem nos ambientes hospitalares eles têm esteticamente outra referência e o seu colorido e ritmo são distintos. Ele é por natureza extra cotidiano. Sua presença alivia tensões, deixa mais leve o ambiente, pois traz momentos de alegria, em que o foco não está na enfermidade e sim no encontro entre as pessoas e o palhaço. De certa forma, humaniza as relações, uma vez que os papéis se transformam e o imaginário vem à tona para fazer o paciente virar médico, o médico assistente e o acompanhante alguém que precisa de cuidados para tirar a água do joelho... O riso então cria um momento de relaxamento. No circo, o palhaço também tem esta atribuição de relaxar, de humanizar o que se vê, pois o que se faz ali é muito excepcional e quase inumano. O trapezista, embora seja uma pessoa como todas as outras, pode voar. O mágico faz coisas impossíveis de acontecer. O palhaço, com suas ações, aproxima o público de sua realidade, pois como todos, ele cai, tenta fazer algo fantástico e revela o truque. Ele erra. O palhaço é o espelho que nos reflete para nos vermos de modo risonho.

A partir de seu ciclo nos Doutores da Alegria, você teve novas percepções sobre seu trabalho como artista em outros contextos da sociedade? Como você visualiza que as experiências vividas na ONG dialogam hoje com seu fazer artístico?

Comecei o meu trabalho muito ligado às referências do palhaço de circo, Os Trapalhões, Três Patetas. Então, tinha um trabalho muito amplo, espalhafatoso e sempre pensando em fazer o trabalho para que ele aparecesse, como se estivesse num picadeiro, com gestos grandes e voz num volume acima do normal. Todo o tempo queria agir, agir e agir para prender a atenção da plateia. Depois que fui para o hospital, entendi que o trabalho pode ser mais sutil, mais delicado e pontual. Ali, compreendi a pausa e o silêncio. Assim, Zabobrim teve que lidar com situações em que o riso não era o primeiro canal de cumplicidade e nem a ação, o seu maior atrativo. Vivenciei a força da escuta do palhaço, a importância da passividade na relação como o público e experimentei muito esta outra ligação com os espectadores. Para mim, o trabalho no hospital me fez aproximar, não só espacialmente, do público. Foi, neste contexto, que meu palhaço se humanizou. A partir desta humanização, tive outro olhar para o mundo e comecei a interagir de outra forma. Esta herança carrego comigo para onde eu for.

Ao assistir seu trabalho como palhaço, eu percebo uma forte conexão com o olhar da plateia, presente do início ao fim de suas atuações. Caso concorde com esta percepção, você poderia falar um pouco sobre o que te mobiliza a buscar constantemente o olhar do outro, em momento de atuação?

Concordo com sua análise e, de fato, busco o olhar da plateia para criar cumplicidade, empatia. O palhaço está a todo o momento vendo e jogando com as reações do público, então é fundamental que ele tenha um olhar aberto a ele. Mais que tudo, o palhaço dialoga com a plateia. A comunicação se faz com fala e a escuta, ação e 
reação. Por isso, o olhar para o público tem muita importância, já que através dele eu tenho um forte radar para captar as reações e escutar o que se passa na plateia. $E$ com esta escuta, posso dimensionar os melhores caminhos para a interação.

\section{Por fim, você gostaria de relatar alguma experiência significativa em seu processo enquanto palhaço, dentro ou fora do contexto hos- pitalar?}

São muitas experiências ao longo do tempo. Muitos encontros. O encontro Sue Morrison, mestre canadense que trabalha o palhaço a partir da relação dos palhaços das tribos indígenas norte-americanas, foi um ponto de mudança na minha trajetória de palhaço. Foi com ela que fiz o meu primeiro curso de aprofundamento do trabalho, pois já vinha passando por grandes experiências ao trabalhar no hospital. Foi neste curso que consegui solidificar mais a corporeidade e presença do Zabobrim e foi quando encontrei minha parceira Andreia Macera, com quem fiz o meu primeiro espetáculo de palhaço: A Julieta e o Romeu. Foi depois destes encontros que meu trabalho deu um salto muito grande. Na relação com outros nos afirmamos enquanto indivíduos e, assim, o palhaço vai tomando contornos mais claros e fortes da sua própria persona. Outro momento significativo foi ter ido para Argentina trabalhar na rua em 2003, tendo a experiência de chamar a atenção do público passante, abrir uma roda, começar a apresentar um espetáculo e no final passar o chapéu. Fazia duas apresentações por noite num calçadão em San Bernardo, Mar del Plata. Estar sozinho e ter que segurar um público que não te conhece, que pode ir embora a qualquer momento, foi sem dúvida uma incrível experiência. Viver cada vitória e derrota deste momento, descobrindo caminhos com a interação do público, foi sem dúvida muito significativo para o meu trabalho. Por último, conto uma experiência que me fez afirmar que o mais importante do palhaço, é o encontro com o público. Fui apresentar o espetáculo WWW para FREEDOM na Cidade do México. Preparei-me, estudei espanhol, traduzi o espetáculo, e lá fui eu. Nesta peça, eu uso muitos fogos de artifício para causar alguns efeitos. Acontece que como faria uma viagem internacional, fiquei receoso de levar fogos do Brasil e ter problemas no aeroporto. Ser preso como terrorista por portar estalinhos de São João seria uma vergonha! Para mim e para os terroristas... Bem, então comprei todos os fogos na Cidade do México, no dia da apresentação, pois tinha chegado na noite anterior. No espetáculo, os fogos, ou melhor, todos os fogos falharam e num primeiro momento pensei que a apresentação estaria perdida. Quando vi que não tinha jeito e que os fogos realmente não estavam ao meu favor, inclui isto no espetáculo jogando com o que estava acontecendo e deixando isto claro para o público. Apesar destas falhas, o público estava comigo, pois o palhaço estava passando por problemas que todos estavam sabendo e assim estivamos juntos, rimos juntos do que se passava. Acabou sendo um encontro maravilhoso!

\section{Gostaria de fazer mais alguma colocação?}

Gostaria de dizer que um palhaço não se faz sozinho. Ele é o resultado de muitos elementos. Tanto dos mestres que vieram antes, como das suas referências esté- 
ticas e de todo o trabalho dos palhaços que nos antecederam. É resultado do imaginário do público e do seu senso de humor. O riso revela características daqueles que riem. Sendo assim, podemos investir em um riso transformador que nos revolucione em nossas visões e que possa fazer uma humanidade mais potente e tolerante, mais compreensiva e autônoma. O palhaço é o instrumento de uma manifestação ontológica da humanidade. Viva o palhaço e viva nossa possibilidade de transformação e riso!!! Para terminar, quero agradecer a oportunidade de ceder esta entrevista, agradecer o seu interesse em me entrevistar.

\section{Referências}

BARRACÃO TEATRO (Campinas). Site da organização: o grupo. 2016. Disponível em: <http://barracaoteatro.com.br/>. Acesso em: 19 set. 2016.

DOUTORES DA ALEGRIA (São Paulo). Balanço 2014. São Paulo: Doutores da Alegria, 2014.

KÁSPER, Kátia Maria. Experimentações clownescas: os palhaços e a criação de possibilidades de vida. Campinas, 2004. Tese (Doutorado) - Faculdade de Educação, Universidade Estadual de Campinas, 2004.

Recebido em: 19/09/2016

Aprovado em: 08/11/2016 